\title{
PLANEJAMENTO E GESTÃO URBANOS EM SOROCABA-SP: ANÁLISE DAS POLÍTICAS PÚBLICAS DE HABITAÇÃO POPULAR
}

\section{Urban planning and management in Sorocaba-SP: analysis on public politics of popular habitation}

\author{
Sandro Ivo de MEIRA ${ }^{1}$
}

\section{RESUMO}

Esse trabalho centrou-se na análise do planejamento e gestão urbanos voltados às políticas de habitação popular na cidade de Sorocaba, interior do estado de São Paulo, no período 1989 a 2004. Como principal instrumento de avaliação das políticas públicas utilizou-se o Plano Diretor Municipal aprovado em 2003 em comparação às diretrizes do Estatuto da Cidade e da Constituição Federal, que possibilitaram mais autonomia para os governos locais gerirem o crescimento urbano de maneira que os investimentos públicos se baseassem no princípio da função social da cidade e da própria propriedade. $\mathrm{O}$ estudo do planejamento urbano restringiu-se à análise do Plano Diretor em que a avaliação das ações públicas na habitação popular no referido período permitiu elucidar a maneira com que a legislação urbana municipal é aplicada no sentido de manter as práticas especulativas.

\section{Palavras-chave:}

Planejamento e gestão urbanos; Plano Diretor; Estatuto da Cidade; política habitacional; Sorocaba-SP.

\begin{abstract}
This work is centered in the analysis of the urban planning and management directed to the politics of popular habitation in the Sorocaba city, interior of the state of São Paulo, in period from 1989 to 2004. With main instrument of evaluation of the public politics approved Municipal Managing Plan in 2003 in comparison to the lines of direction of the Statute of the City and the Federal Constitution was used to give greater autonomy to local governments to manage the urban growth thus the public investments it is based on the principle of the social function of the city and the proper property. The study of the urban planning was restricted to the analysis of the Managing Plan where the evaluation of the public actions on the popular habitation in the related period allowed to elucidate the way with that the municipal urban legislation is applied in the direction to keep the speculative actions.
\end{abstract}

\section{Key-words:}

Urban planning and Management; Managing Plan; Statute of the City; Habitation Politics; Sorocaba-SP.

${ }^{1}$ Professor dos Ensinos Fundamental e Médio das Redes Pública e Particular do Estado de São Paulo. Mestre em Geografia pela Universidade Federal do Paraná. 


\section{INTRODUÇÃO}

Um dos instrumentos que amparam a realização de ações e políticas públicas direcionadas a solucionar e minimizar os problemas sociais das cidades é o Plano Diretor, instituído pelo Estatuto da Cidade como o principal meio de promover o crescimento ordenado e democrático dos espaços urbanos. O Plano Diretor, além de ordenar o crescimento urbano, tem também a função de propor medidas e estratégias aos agentes públicos municipais para que a função social da cidade e da propriedade seja cumprida na sua plenitude, principalmente com a retenção da especulação imobiliária e a inibição do crescimento das periferias urbanas.

A noção de periferia utilizada neste texto é definida de acordo com a acepção de Kowarick (2000, p. 43), em que:

No geral [as periferias são áreas] com graves problemas de saneamento, transporte, serviços médicos e escolares, em zonas onde predominam casas autoconstruídas, favelas ou o aluguel de um cubículo situado no fundo de um terreno em que se dividem as instalações sanitárias com outros moradores: é o cortiço da periferia. Zonas que abrigam população pobre, onde se gastam várias horas por dia no percurso entre a casa e o trabalho. Lá impera a violência. Dos bandidos, da polícia, quando não dos "justiceiros". Lá é por excelência o mundo da subcidadania.

Esta concepção é complementada com a definição de Mautner (1999, p. 253-254) de que a periferia “... é de fato um local onde vivem os pobres, é socialmente segregada, e o preço da terra é baixo". Ela é também, ao mesmo tempo, um local mutante, sempre reproduzida em novas extensões de terra, enquanto velhas periferias são gradualmente incorporadas à cidade. Utiliza-se, portanto, a idéia de periferia social, em que esse termo refere-se ao local de segregação sócio-espacial e negligência do poder público no que tange aos elementos urbanos mínimos para uma sobrevivência digna (infraestrutura urbana e habitabilidade).

Assim, este texto se propõe a demonstrar o planejamento e gestão urbanos na cidade de Sorocaba$\mathrm{SP}$ com enfoque às questões ligadas à promoção de políticas públicas voltadas à população de baixa renda no que diz respeito à habitação. Definiu-se como objeto de análise a habitação popular contida no Plano Diretor Municipal de Sorocaba aprovado em 2004 e as gestões municipais entre os anos de 1989 e 2004 . Esse período representa aquele em que a política urbana, como indicado anteriormente, passa a ter mais autonomia pelos agentes públicos locais e também representa um período em que a população de Sorocaba apresentou um crescimento vertiginoso ${ }^{2}$, o que naturalmente agrava os problemas de moradia caso não haja interferência ativa do poder público.

\section{DIRETRIZES DA POLÍTICA URBANA CONTIDAS NO ESTATUTO DA CIDADE}

Para o Instituto Cidadania (2000, p. 38), existe no Brasil um novo padrão de crescimento das cidades em que "a maior parte desse crescimento se dá na periferia urbana, ou seja, trata-se de uma expansão homogênea da pobreza", e que o crescimento é proporcionalmente maior das cidades de porte médio em relação às grandes cidades e às metrópoles.

O crescimento (espacial e econômico) das cidades ocorreu e ainda ocorre paralelo a uma negligência nos investimentos públicos coletivos, sem a preocupação em garantir a geração de emprego e renda e a inclusão dos menos favorecidos na sociedade. Essas condições proporcionaram o crescimento ilegal e clandestino das grandes e médias cidades brasileiras em que a referida parcela da população, impedida de sua real inclusão socioespacial, se obrigou a procurar nas periferias e no trabalho informal o seu local de vivência e fonte de renda, respectivamente.

Para que se alcance o bem coletivo, as ações políticas e o planejamento não devem estar focados somente no mercado imobiliário, do capital e das elites fundiárias (BRASIL, 2005, p. 37), mas é necessário que se pense em planos que contenham novos paradigmas de desenvolvimento urbano e que estejam em conformidade aos interesses sociais da propriedade e da própria cidade. Isto também é defendido por Souza (2003, p. 60-61) na sua concepção de desenvolvimento no sentido de uma "mudança social positiva", bem como na proposta intersetorial de construção da cidade.

Como aponta o Ministério das Cidades (BRASIL, 2005, p. 39):

Apenas políticas públicas intersetoriais podem transformar as precárias condições de vida nas cidades. É preciso contar nesse processo com organização mais intersetorial e com disposição política, para efetivamente romper com práticas fragmentadas, elaboradas por instâncias governamentais setorializadas.

${ }^{2}$ Em Sorocaba, segundo o Censo Demográfico 2000 (IBGE, 2001), a taxa de crescimento anual na década de 1990 estaria em torno de 3,47\%, passando de 365.529 habitantes em 1980 para 547.075 em 2004. 
É sob essa perspectiva de análise que a delimitação da escala espacial para estudar um item da política urbana (a habitação popular) ficou direcionada ao município. Também a Constituição Federal (BRASIL, 1997, art. 182) e o Estatuto da Cidade delegam aos municípios a função de coordenar e executar propostas que solucionem os problemas de ordem local em sua política urbana, incluindo-se aí o déficit habitacional e o crescimento desordenado e excludente das cidades.

No contato direto com os problemas locais, sob os olhos da população, é que essas propostas podem convergir. O local é a escala mais propícia para identificar os problemas comuns e os diferentes interesses que podem contribuir para a construção social pactuada. O local é propício ao planejamento, à gestão, ao monitoramento participativo e à apropriação do espaço urbano e do espaço político pela população. (BRASIL, 2005, p. 39-40)

Não se nega aqui a importância das atividades econômicas, nem a "emergência constante" de se reverter à crise socioeconômica dos municípios, estados e nação, mas questiona-se a maneira com que os recursos gerados por essas atividades são revertidos para a população por meio da coletivização dos investimentos públicos. Deve-se enfatizar que o desenvolvimento econômico é imprescindível para que se possa realizar o desenvolvimento social, mas que, em decorrência de divergências políticas e empresariais, os investimentos sociais coletivos são, na maioria das vezes, relegados à posteridade.

Segundo a Constituição Federal, cabe ao Poder Público Municipal executar a política de desenvolvimento urbano, conforme diretrizes fixadas em lei, e tem por objetivo "ordenar o pleno desenvolvimento das funções sociais da cidade e garantir o bem-estar de seus habitantes" (BRASIL, 1997, art. 182).

O Município, com base no artigo 182 e no princípio da preponderância do interesse, é o principal ente federativo responsável em promover a política urbana de modo a ordenar o pleno desenvolvimento das funções sociais da cidade, de garantir o bem-estar de seus habitantes e de garantir que a propriedade urbana cumpra sua função social, de acordo com os critérios e instrumentos estabelecidos no Plano Diretor, definido constitucionalmente como o instrumento básico da política urbana. (INSTITUTO PÓLIS, 2001, p. 30)

É, portanto, atribuída ao município a competência privativa para legislar sobre assuntos de interesse social, suplementando as legislações federal e estadual no que for necessário para atender às necessidades locais, promovendo o ordenamento territorial por meio de planejamento e controle, do parcelamento e da ocupação e uso do solo urbano (INSTITUTO PÓLIS, 2001, p. 30).

O Capítulo II - artigos 182 e 183 - da Constituição Federal sobre Política Urbana estabelece os instrumentos para a garantia, no âmbito de cada município, do direito à cidade, do cumprimento da função social da cidade e da propriedade (BRASIL, 2005, p. 12).

No intuito de ordenar o desenvolvimento urbano foi criada a Lei Federal 10.257, de 10 de julho de 2001, denominada Estatuto da Cidade (BRASIL, 2002):

O Estatuto da Cidade, Lei Federal 10.257 de 10 de
julho de 2001 , regulamenta os artigos 182 e 183 da
Constituição Federal e estabelece parâmetros e
diretrizes da política urbana no Brasil. Oferece instru-
mentos para que o município possa intervir nos pro-
cesso de planejamento e gestão urbana e territorial, e
garantir a realização do direito à cidade. (BRASIL,
2005, p. 12)

O Estatuto da Cidade veio reforçar o que há muitos anos se questionava no Brasil sobre uma legislação urbana específica e fortalece uma discussão diferenciada no nível das cidades, pela implantação plena das diretrizes e instrumentos de política urbana previstos nessa lei, que muitas vezes são colocadas de maneira paliativa ou totalmente negligenciadas nos planos municipais.

De acordo com o Ministério das Cidades:

Planejar o futuro da cidade, incorporando todos os
setores sociais, econômicos e políticos que a com-
põe, de forma a construir um compromisso entre cida-
dãos e governos na direção de um projeto que inclua
todos, é o desafio que o Estatuto da Cidade impõe a
todos os Planos Diretores, obrigatórios para cidades
brasileiras [com população superior a 20 mil habitan-
tes ou com interesses particulares de intervenção ur-
banística] até 2006 . (BRASIL, 2005, p. 08)

Neste artigo foi dada maior atenção às Diretrizes e Instrumentos da Política Urbana propostos pelo Estatuto da Cidade e ao Plano Diretor, como subsídios para estudar a questão habitacional em Sorocaba que abrange, principalmente, o envolvimento do poder público municipal em desenvolver o planejamento e a gestão de forma que direcionem suas ações às classes menos abastadas dessa cidade, e a sua utilização dos artifícios legais como:

- Parcelamento, Edificação ou Utilização Compulsórios; IPTU Progressivo no Tempo; Desapropriação com Pagamento em Títulos; Consórcio Imobiliário.

- $\quad$ Outorga Onerosa do Direito de Construir; Direito de Superfície. 
- Operações Urbanas Consorciadas.

- $\quad$ Direito de Preempção.

- Transferência do Direito de Construir

- Usucapião Especial de Imóvel Urbano.

\section{PLANEJAMENTO URBANO DE SOROCABA}

O Plano Diretor de Sorocaba é dividido em três partes, sendo as principais: "Plano Diretor de Desenvolvimento Físico-Territorial" e "Zoneamento, Uso, Ocupação e Parcelamento do Solo", que serão discutidos sucintamente neste item.

O Plano Diretor de Desenvolvimento FísicoTerritorial (PDDFT), que compõe o Título I do Plano Diretor Municipal de Sorocaba de 2004, é analisado neste item de acordo com a proposta metodológica de Souza (2003, p. 200-213) com relação à análise do planejamento e gestão urbanos. A variável que corresponde ao Projeto de Cidade pode se equivaler ao que este autor chama de Idéia-força central, a qual define a abordagem central (objetivo) das ações públicas (planejamento e gestão) no que diz respeito à construção e ordenamento da cidade ${ }^{3}$.

O PDDFT de Sorocaba determina, no seu art. $1^{\circ}$ que trata dos Objetivos e Princípios Fundamentais (PREFEITURA, 2004), o parâmetro norteador da política urbana neste município, ou seja, a referência para a construção da cidade:

Esta lei institui o Plano Diretor de Desenvolvimento Físico Territorial de Sorocaba - instrumento básico da política de desenvolvimento urbano do Município conforme estabelecido pela Lei Orgânica do Município de Sorocaba - definindo objetivos e diretrizes específicas para alcançar o objetivo geral, que é o pleno desenvolvimento das funções sociais da cidade $\mathbf{e}$ da propriedade imobiliária urbana [grifo do autor]. (PREFEITURA, 2004)

Essa primeira análise do Plano Diretor de Sorocaba pode ser enquadrada, de acordo com a proposta metodológica de Souza (2003, p. 208-213), numa tipologia de planejamento urbano do tipo "Rawlsiano" ou "Planejamento e gestão urbanos social-reformistas", que preconizam a justiça social. Contudo, é previsível que qualquer Plano Diretor elaborado ou revisado a partir do Estatuto da Cidade estabeleça como princípio fundamental o "pleno desenvolvimento das funções sociais da cidade e da propriedade". Seria inconstitucional omitir esse princípio numa lei municipal, assim como outros instrumentos que constam como diretrizes para elaboração de uma política urbana pelos municípios.

Escalando as principais funções sociais do ordenamento e desenvolvimento urbanos, o art. $2^{\circ}$ do PDDFT de Sorocaba (PREFEITURA, 2004) estabelece que o município, incluindo todos os agentes públicos e privados que atuam em Sorocaba, deve:

I - Viabilizar a oferta de infra-estrutura e equipamentos coletivos à sua população e aos agentes econômicos instalados e atuantes no Município;

II - Criar condições adequadas à instalação de novos empreendimentos econômicos, garantindo o desenvolvimento do Município como pólo regional de comércio, serviços e produção industrial;

III - Garantir a qualidade ambiental e paisagística, protegendo os recursos naturais.

As funções sociais aqui explicitadas demonstram a preocupação com o ordenamento espacial a fim de subsidiar o crescimento econômico, já que dois dos três incisos que compõem este artigo citam a questão econômica. Não se trata aqui de questionar a importância do poder público municipal em investir em projetos e infra-estrutura que promovam o crescimento econômico do município, gerando emprego e, principalmente, receitas para o próprio município. O que se indaga é a real implementação do próprio objetivo central do atual Plano Diretor citado anteriormente de que as funções sociais da cidade e da propriedade são as principais diretrizes da política urbana no município em questão.

Com relação às funções sociais do município e da cidade, $\mathrm{o}$ art. $3^{\circ}$ do Plano Diretor Municipal (PREFEITURA, 2004) orienta a política urbana no sentido de atingir os seguintes objetivos:

I - Garantir espaço adequado às diversas funções e atividades, de forma compatível com a manutenção do equilíbrio ambiental.

II - Ordenar e controlar a expansão das áreas urbanizadas de forma a

a) preservar os recursos hídricos e demais recursos naturais não-renováveis locais;

b) minimizar deseconomias e impactos negativos sobre o meio ambiente no processo de ampliação das áreas urbanizadas; e

\footnotetext{
${ }^{3}$ Deve-se, necessariamente, reafirmar que o enfoque principal de política urbana defendido neste trabalho é baseado nas propostas de Souza (2003) de desenvolvimento urbano que engloba o aumento de justiça social e melhoria da qualidade de vida, e também aos princípios do Estatuto da Cidade (BRASIL, 2002) referentes às funções sociais da cidade e da propriedade urbana.
} 
c) Permitir o correto dimensionamento e a programação da expansão dos sistemas de equipamentos e serviços públicos.

III - Promover o equilíbrio entre os usos e a intensidade de ocupação do solo e a disponibilidade de infra-estrutura, visando a otimização dos investimentos públicos;

IV - Minimizar os conflitos de vizinhança;

V - Preservar o patrimônio cultural local, com destaque para os edifícios de interesse histórico e arquitetônico;

VI - Adequar a malha viária e os serviços de transporte coletivo à evolução das necessidades de circulação de pessoas e bens;

VII - Implementar, estimular e apoiar a melhoria da habitação de interesse social;

VIII - Integrar os programas de saneamento e drenagem à política de ordenação do território.

Os artigos $2^{\circ}$ e $3^{\circ}$ supracitados demonstram muita proximidade com o objetivo central do Plano Diretor de Sorocaba - classificado anteriormente como um planejamento que prioriza a justiça social. No entanto, o que fica claro quando se coloca questões ligadas às áreas sociais - como: minimizar deseconomias e impactos negativos sobre o meio ambiente, promover o melhor aproveitamento da infra-estrutura urbana de modo a reduzir os gastos públicos e, principalmente, implementar, estimular e apoiar a melhoria da habitação de interesse social - é o jargão comum contido nos instrumentos pela promoção de melhorias para a coletividade, quando o que realmente acontece é o cumprimento de prerrogativas da legislação superior sem que tenham efetividade prática.

O objetivo central do Plano Diretor de Sorocaba (art. $1^{\circ}$ ) demonstrou a preocupação em se alcançar o pleno desenvolvimento das funções sociais da cidade e da propriedade imobiliária urbana, no entanto, o que se observa é uma tendência do planejamento em se encaixar num padrão próximo aos princípios de vários tipos de planejamento, como o "planejamento físicoterritorial clássico", o "planejamento sistêmico", o "planejamento com perspectivas 'mercadófilas'” e até o "New Urbanism", que apregoam uma breve citação da questão social no discurso ao mesmo tempo em que se contradizem ao estabelecer parâmetros que tornam a cidade mais racional, modernizada e mais "competitiva" no âmbito econômico.

Para o Instituto Pólis (2001, p. 46), os princípios e diretrizes da política urbana norteadora de um Plano Diretor devem obedecer aos princípios estabelecidos na Constituição Federal e as diretrizes gerais da política urbana estabelecidas no Estatuto da Cidade, respeitando, sobretudo, os seus artigos $2^{\circ}$ e $39^{4}$. Portanto, é fundamental que um Plano Diretor estimule a função social da propriedade, o desenvolvimento sustentável, as funções sociais da cidade, a igualdade e a justiça social e a participação popular, como estabelecem as seguintes diretrizes gerais da política urbana, contidas no art. $2^{\circ}$ do Estatuto da Cidade (BRASIL, 2002).

A função social da cidade é enfocada pelo Instituto Pólis (2001, p. 47) na redução de desigualdades sociais, promoção da justiça social e melhoria da qualidade de vida urbana, com o intuito de promover medidas que impeçam os setores públicos e privados de estabelecerem ações que ocasionem a exclusão/segregação de grupos e comunidades carentes: "Enquanto essa população não tiver acesso à moradia, transporte público, saneamento, cultura, lazer, segurança, educação, saúde, não haverá como postular a defesa de que a cidade esteja atendendo à sua função social".

No seu artigo primeiro, o PDDFT de Sorocaba se caracteriza como um instrumento de priorização da organização urbana no sentido de adequar o uso coletivo e a qualidade ambiental. Não se evidencia neste Plano Diretor a necessidade de realizar ações que permitam ou facilitem o acesso à moradia pelas camadas mais carentes da sociedade, ou que, como pode-se observar no artigo $4^{\circ}$ supracitado, a ação pública esteja voltada na retenção da especulação que atinge diretamente (e negativamente) as parcelas mais pobres da sociedade, como prevê o artigo $2^{\circ}$ do Estatuto da Cidade (BRASIL, 2002).

O escopo adotado pelo PDDFT de Sorocaba aponta para a característica de um plano que em seu "Projeto de Cidade" não se limita a uma esfera estritamente físico-territorial, mas também não pode ser enquadrado como um planejamento social abrangente. De certa maneira fica claro que o ordenamento apresentado neste instrumento se responsabiliza por ser o principal promotor das funções sociais da cidade, mas contraditoriamente indica um zoneamento muito restrito a um planejamento físico-territorial, com a presença "sim-

${ }^{4}$ (CAPÍTULO III: Do Plano Diretor) Art. 39. A propriedade urbana cumpre sua função social quando atende às exigências fundamentais de ordenação da cidade expressas no plano diretor, assegurando o atendimento das necessidades dos cidadãos quanto à qualidade de vida, à justiça social e ao desenvolvimento das atividades econômicas, respeitadas as diretrizes previstas no art. 20 desta Lei. (BRASIL, 2002) 
bólica" de algumas citações referentes à promoção de melhoria na qualidade de vida e justiça social, relegando a responsabilidade maior para os "planos setoriais" que ainda devem ser elaborados.

Teoricamente apontada por Souza (2003, p. 119, $123,131)$, a forma convencional de planejamento - e gestão -, acrítica aos modelos de desenvolvimento urbano como sinônimo de modernização da cidade, consiste na concepção de "planejamento como a atividade de elaboração de planos de ordenamento espacial para a 'cidade ideal". A "idéia-força central do urbanismo modernista, a modernização da cidade, é, ao mesmo tempo, [...] compartilhada com a concepção do 'planejamento físico-territorial' clássico em geral, o mesmo aplicando-se às demais idéias-força como ordem e racionalidade".

Essa análise do PDDFT de Sorocaba aponta para a delimitação das variáveis "atitude em face do mercado" e "referencial político-filosófico" em que o planejamento neste município é regido por forças políticas que adotam o padrão da menor intervenção do Estado com relação ao mercado imobiliário. Entretanto, o chamado "criticismo moderado" reduz-se a demonstrar no planejamento certa "domesticação" e a aceitação pragmática do mercado imobiliário sem restrições na cidade. Isto inviabiliza o objetivo central do próprio Plano Diretor de promover, como rezam as leis Federais (Constituição e Estatuto da Cidade), as funções sociais da cidade e da propriedade, caracterizando o planejamento urbano do tipo que envolve maiores "perspectivas mercadófilas".

A principal característica do planejamento urbano de Sorocaba sempre foi a correspondência do crescimento urbano aos anseios dos investimentos industriais que foram marcantes na cidade durante o século $X X$. Como demonstram os fascículos do jornal Cruzeiro do Sul (SOROCABA, 2004, p. 274-288), as prioridades desde a elaboração do Plano Diretor de Desenvolvimento Integrado - PDDI de 1971 até a elaboração do atual Plano Diretor de Desenvolvimento Físico-Territorial do Município de Sorocaba (PDDFTS) foram o ordenamento do crescimento urbano com segurança para a manutenção do crescimento econômico, principalmente o industrial.

A transformação do distrito de Votorantim em município na década de $1960^{5}$ e a conseqüente perda de arrecadação das atividades industriais concentradas nessa localidade fizeram com que o Plano Diretor de Desenvolvimento Integrado de 1971 revisse a possibilidade de instalação de uma nova zona industrial em Sorocaba que não fosse tão próxima da área urbana, mas também não muito distante dela (SOROCABA, 2004, p. 278).

Durante o processo de votação na Câmara Municipal de Sorocaba do atual Plano Diretor, várias emendas foram anexadas a esta lei no Zoneamento Municipal com vistas à diminuição dos conflitos de interesses entre os empresários e as áreas residenciais que cresceram e foram "abocanhadas" pelos empreendimentos na zona industrial (SOROCABA, 2004, p. 280-281).

Em Sorocaba, observa-se que não houve uma preocupação em delimitar, especificar ou acrescentar no zoneamento as áreas ou zonas urbanas subutilizadas ou não-utilizadas, que deveriam, portanto, estar sujeitas à aplicação dos referidos instrumentos de política urbana amparados pelo Estatuto da Cidade. Em vez disso, o PDDFT de Sorocaba aponta para a necessidade de se produzir uma legislação específica que garanta a ordenação do crescimento urbano baseado, principalmente, na estrutura física do município (geologia, hidrografia, topografia etc) e na separação das atividades urbanas por zonas de uso (zona central; zona predominantemente institucional; zonas residenciais 1, 2 e 3 ; zona industrial; zona de atividades especiais; zona de chácaras urbanas; zona de conservação ambiental; corredores de comércio e serviços 1 e 2; corredores de comércio e indústria 1 e 2; corredor de circulação rápida) ${ }^{6}$.

É claro que a criação de planos, projetos e legislações específicas deve ser feita quando o Plano Diretor for aprovado, até mesmo no sentido de atualização constante do próprio plano. No entanto, isso não desobriga o atendimento às determinações do Estatuto da Cidade de se apontar no próprio Plano Diretor as áreas da cidade nas quais os instrumentos urbanísticos devem ser aplicados com mais veemência e a delimitação das áreas que devem ser utilizadas para habitação de interesse social. O que se observa no PDDFT de Sorocaba é que se estabelecem novos prazos para elaboração de planos setoriais que atentem para esta questão. Assim, a morosidade da confecção e execução desses planos proporciona o abarrotamento periférico das populações desassistidas pelo poder público.

\footnotetext{
${ }^{5} \mathrm{Em} 1^{\circ}$ de dezembro de 1963 foi realizado um plebiscito no distrito industrial de Votorantim, até então pertencente a Sorocaba, em que a maioria dos votos aprovou a emancipação política daquela localidade. A instalação oficial do município de Votorantim ocorreu em 27 de março de 1965 (PREFEITURA, 2005).

${ }^{6}$ Esses itens, referentes aos índices urbanísticos, serão tratados no subcapítulo posterior: Zoneamento, Uso, Ocupação e Parcelamento do Solo, com as variáveis de Souza (2003): "grau de interdisciplinaridade", "permeabilidade em face da realidade" e "grau de abertura para com a participação popular".
} 
O capítulo IV do PDDFT, que trata das Diretrizes para Planos e Projetos Setoriais, na seção I sobre a Habitação de Interesse Social, indica que cabe à Prefeitura apresentar um Plano Municipal de Habitação em até 24 meses contados a partir da publicação do Plano Diretor de Sorocaba. Isso com o intuito de cadastrar as habitações irregulares e levantar as necessidades habitacionais excluídas do atendimento do mercado formal (PREFEITURA, 2004).

No entanto, o município que tem seu Plano Diretor, obrigatoriamente deve também, para cumprir a plenitude da função social da propriedade e da cidade, identificar e delimitar no próprio plano as áreas que não estão cumprindo sua função social (INSTITUTO PÓLIS, 2001, p. 55).

Os instrumentos apontados pelo Estatuto da Cidade para promover a função social da cidade e da propriedade foram somente anexados à lei do Plano Diretor de Sorocaba no Capítulo III, que se refere aos Instrumentos da Política Urbana (PREFEITURA, 2004, p. 1017). Não há nenhuma referência pragmática de implementação deles, o que indica que a aprovação dessa Lei foi feita de forma a garantir a aprovação do Plano Diretor apenas para não deixar cair na inconstitucionalidade.

Esses instrumentos deveriam servir como o principal auxílio fiscal do poder público para organizar a expansão da cidade e regular o cumprimento da função social da propriedade imobiliária urbana.

A Seção I do PDDFT de Sorocaba (PREFEITURA, 2004), que trata do Parcelamento, Edificação ou Utilização Compulsórios, no seu art. 29, diz que:

A Prefeitura Municipal de Sorocaba poderá [sem grifo no original] determinar o parcelamento, edificação ou utilização compulsórios de imóveis situados dentro do perímetro urbano, definidos no mapa de zoneamento, quando considerados sub-utilizados e quando houver interesse da coletividade para sua ocupação. (PREFEITURA, 2004, p. 10-11)

A mesma seção apresenta, ainda, a possibilidade de a Prefeitura Municipal de Sorocaba aplicar o IPTU progressivo no tempo aos proprietários que não cumprirem com a notificação referente ao parcelamento, edificação ou utilização. No entanto, o parágrafo primeiro do artigo supracitado indica que deverá ser criada uma lei específica para determinar o perímetro das áreas em que este instrumento poderá ser aplicado, sem discriminar, inclusive, a possibilidade da aplicação da Desapropriação com Pagamento em Títulos prevista no Es- tatuto da Cidade $^{7}$ (BRASIL, 2002), caso haja a ocorrência de cinco anos de cobrança do IPTU progressivo sem que o proprietário tenha cumprido a obrigação de parcelamento, edificação ou utilização.

Neste e em outros itens observados no Plano Diretor de Sorocaba, a questão da obrigatoriedade do poder público municipal em fazer cumprir a função social da cidade e da propriedade fica relegada aos planos setoriais (neste caso, o Plano Municipal de Habitação), e evidencia a anexação simples dos instrumentos do Estatuto da Cidade. As únicas áreas delimitadas pelo Plano Diretor de Sorocaba que são passíveis de aplicação de algum instrumento referem-se às Operações Urbanas Consorciadas.

Reforça essa observação a determinação do item I do art. 42 do Estatuto da Cidade (BRASIL, 2002), de que o Plano Diretor deverá conter, no mínimo,

a delimitação das áreas urbanas onde poderá ser aplicado o parcelamento, edificação ou utilização compulsórios, considerando a existência de infra-estrutura e de demanda para utilização, na forma do art. $5^{\circ}$ desta Lei [supracitado].

Em outubro de 2003, já após o fim das audiências públicas organizadas pelo legislativo, o promotor José Carlos de Freitas, do Centro de Apoio Técnico e Operacional da Procuradoria Geral de Justiça do Estado propôs

a retirada do projeto do novo Plano Diretor do Município de Sorocaba da pauta de votação da Câmara a fim de serem corrigidas "imperfeições" no texto. A versão da proposta que o Legislativo começa a votar em novembro pode, segundo alertou Freitas, motivar questionamentos judiciais (PROMOTOR, 2003).

Dentre as observações do promotor José Carlos de Freitas está a falta de mapeamento das áreas ociosas do município sujeitas ao IPTU Progressivo, apontando ainda, que Sorocaba apresenta cerca de cinqüenta mil lotes vagos, podendo agir os instrumentos do Estatuto da Cidade para garantir a função social da propriedade e inibir a especulação imobiliária.

Mesmo que apareça - muitas vezes forçados pelas diretrizes da legislação federal ou estadual - algum artigo ou indicação no Plano Diretor de que a função social da propriedade e da cidade é prioridade da ação pública municipal no meio urbano a indefinição das áreas onde poderiam ser aplicados os instrumentos previstos no Estatuto da Cidade impede o exercício da fa-

${ }^{7}$ Capítulo II, Seção IV, art. $8^{\circ}$. 
culdade conferida ao Poder Público Municipal de aplicar esses instrumentos para que a propriedade urbana tenha realmente seu destino almejado pela sociedade (INSTITUTO PÓLIS, 2001, p. 63).

Quanto à habitação de interesse social, objeto de estudo deste artigo, o Plano Diretor de Sorocaba ${ }^{8}$ dispõe que a Prefeitura Municipal

poderá [sem grifo no original], através de lei municipal específica, criar Áreas de Especial Interesse Social para a Habitação, com os seguintes objetivos: I promover a regularização fundiária em assentamentos irregulares nos termos da Legislação Federal pertinente; II - promover a execução de habitações de baixo custo (PREFEITURA, 2004).

É interessante como alguns itens que tratam especificamente da questão da moradia popular na cidade são indicados como podem e não como devem ser regulamentados pela Prefeitura. Este simples termo na legislação municipal, que aparece em outros itens referentes à promoção da função social da cidade e da propriedade, acaba, novamente, desobrigando as ações públicas de realizar investimentos direcionados às áreas sociais, sobretudo a habitação de interesse social por meio dos Programas Habitacionais Populares.

\section{GESTÃO URBANA - POLÍTICA HABITACIONAL}

Desde o ano de 1997, a Prefeitura Municipal de Sorocaba não realiza nenhum programa habitacional com recursos próprios ou em parceria com outras esferas de governo ${ }^{9}$. Contraditoriamente, um relatório sobre a questão habitacional apresentado em novembro de 1996 já apontava para a necessidade constante de investimentos em programas e projetos na área da habitação popular por parte da Prefeitura Municipal de Sorocaba. Justifica o relatório da antiga Secretaria da Habitação que:

Além do baixo poder aquisitivo da população, o que não possibilita a conquista ou usufruto da moradia são outros fatores que agravam o problema habitacional, tais como oferta e demanda. Trata-se de uma defasagem estabelecida entre a necessidade social de habitação e a produção de moradias e serviços. Disto resulta todo um ciclo cumulativo, que vai aos poucos tornando impossível na vida do trabalhador o acesso a moradia. Todo homem necessita de abrigo, e a satisfação desta necessidade básica humana de- veria ser acessível a todos, como direito, quer como conquista pessoal, quer como subsídio público [sem grifos no original]. (PREFEITURA, 1996)

Naquela época, a própria Secretaria Municipal de Habitação (Sehab) classificava o problema da habitação como uma situação de precariedade que atinge o poder público, de maneira que o déficit habitacional não é um problema isolado, mas uma mazela que envolve direta e indiretamente a falta de acesso ao emprego, crédito habitacional e a escassez da oferta de moradias populares acessíveis a população de baixa renda (PREFEITURA, 1996).

Um primeiro equívoco que se pode observar entre as administrações municipais posteriores a 1996 e o referido relatório da situação habitacional de Sorocaba é a não continuidade ou realização dos projetos de regularização de áreas ocupadas e a orientação de aquisição e construção de novas moradias, com o intuito de inibir novas ocupações irregulares e diminuir o déficit habitacional da cidade.

De acordo com o Decreto n. 8.555, de 21 de junho de 1993, assinado pelo então prefeito Paulo Francisco Mendes, cabia, naquela época, à Secretaria Municipal de Habitação, a responsabilidade de planejar e desenvolver a política habitacional no município, em que:

Entende-se como planejamento e desenvolvimento da política habitacional do Município, além da implantação dos projetos habitacionais, a proposição, acompanhamento e implantação de melhorias e equipamentos urbanos no âmbito municipal, por seus próprios meios ou em conjunto com outras Secretarias e/ou órgãos públicos ou instituições privadas. (PREFEITURA, 1996)

Em todo o Estado de São Paulo, o principal agente promotor de habitação de interesse social é a Companhia de Desenvolvimento Habitacional e Urbano (CDHU), que tem um de seus escritórios localizado no município de Sorocaba, atendendo sessenta e dois municípios da região.

De acordo com própria CDHU (2004), o déficit habitacional primário do Estado de São Paulo está em torno de 400 mil unidades, portanto, é de responsabilidade da Secretaria da Habitação a condução da política habitacional do Governo do Estado. Ela traça:

[...] diretrizes, estabelece metas, planeja e desenvolve programas específicos, objetivando, através da

${ }^{8}$ Seção V, Capítulo III, Título I

9 Segundo depoimentos da arquiteta da Área de Habitação Social da Secretaria de Edificações e Urbanismo (Seurb), Ângela Cristina S. de Jesus, em janeiro de 2005. 
CDHU - Companhia de Desenvolvimento Habitacional e Urbano do estado de São Paulo, a construção de moradias populares destinadas à população de baixa renda, com rendimento entre 1 e 10 salários mínimos. (CDHU, 2004)

Segundo o economista Edgard Pereira, da CDHUSorocaba, a estimativa do déficit habitacional para o município de Sorocaba é por volta de 15 mil unidades ${ }^{10}$, podendo ser questionado, já que há um consenso entre os institutos de pesquisa especializados nesta área sobre a dificuldade da definição de déficit habitacional e a própria contagem desse índice. De acordo com outras fontes, o déficit habitacional desta cidade pode variar entre $11.687 \mathrm{e}$ 30.000 moradias (DÉFICIT, 2004; PLENÁRIA, 2004).

A concepção de déficit habitacional aqui utilizada corresponde à definição do Projeto Moradia (INSTITUTO CIDADANIA, 2001, p. 50-51) de que este está dividido em duas vertentes distintas: "'déficit de moradias' e déficit de 'habitabilidade', relacionado com as submoradias, e assim entendido como o fosso ou desnível existente entre os padrões de moradia digna e as características que elas apresentam".

Com relação aos imóveis urbanos não utilizados, os dados da Seurb (PREFEITURA, 1996) demonstram que em 1996 a cidade de Sorocaba apresentava aproximadamente 11.293 imóveis desocupados, e em 2004, eram aproximadamente 50.000 lotes urbanos que não estavam sendo utilizados, ficando, portanto, à disposição da especulação imobiliária e descumprindo a sua função social estabelecida no Estatuto da Cidade.

Um dos problemas, inclusive apontados na análise anterior sobre o Plano Diretor de Sorocaba, se refe- re à falta de um mapeamento consistente das áreas (lotes ou glebas) ou imóveis que fossem subutilizados ou não utilizados. Nestas áreas e imóveis poderiam ser aplicados os instrumentos de política urbana previstos pela Legislação Federal: parcelamento, edificação ou utilização compulsórios, IPTU progressivo no tempo e a desapropriação com pagamentos em títulos (BRASIL, 2002, p. 29-44).

Dentre esse quadro de déficit habitacional contraditório apresentado em Sorocaba, destacam-se as ações realizadas pela CDHU e os programas realizados pela Crhis $^{11}$, que entre os anos de 1992 e 1998 promoveram a construção de 5.490 moradias na cidade (Quadro 1).

Vale lembrar - para não se cometer o erro de confundir as datas das assinaturas dos programas habitacionais com as determinadas gestões municipais - que os anos das entregas não correspondem aos das assinaturas dos contratos entre a Prefeitura Municipal de Sorocaba, CDHU e/ou a Cohab-Crhis.

Os empreendimentos realizados pela CDHU em Sorocaba no período de 1994 a 1998 foram dos tipos: "Núcleo Habitacional por Empreitada Global (E.G.)" e "Chamamento Empresarial".

Neste tipo de programa (E.G.) realizado no interior do estado de São Paulo, independentemente se as construções forem horizontais ou verticais, cabe à Prefeitura apresentar a iniciativa em realizar o empreendimento, a indicação da área e doação dos terrenos e a realização das obras de infra-estrutura urbana. Já a CDHU entra com a elaboração dos projetos técnicos, as obras de edificação e as obras infra-estruturais condominiais (CDHU, 2004).

\begin{tabular}{|c|c|c|c|c|c|c|c|}
\hline & \multicolumn{7}{|c|}{ UNIDADES HABITACIONAIS COMERCIALIZADAS (por ano) } \\
\hline EMPRESAS & 1992 & 1993 & 1994 & 1996 & 1997 & 1998 & TOTAL \\
\hline CDHU & 0 & 0 & 485 & 56 & 515 & 928 & 1.984 \\
\hline Cohab-Crhis & 2.000 & 1.506 & 0 & 0 & 0 & 0 & 3.506 \\
\hline
\end{tabular}

QUADRO 1 - MORADIAS POPULARES COMERCIALIZADAS EM SOROCABA ENTRE OS ANOS DE 1992 A 1998

FONTES: CRHIS, 2004; CDHU, 2005.

NOTAS: ALGUMAS INFORMAÇÕES A RESPEITO DAS AÇÕES DA CDHU EM SOROCABA FORAM ESCLARECIDAS PELO ECONOMISTA EDGARD PEREIRA EM FEVEREIRO DE 2005.

ORGANIZAÇÃO: SANDRO IVO DE MEIRA.

\footnotetext{
${ }^{10}$ Dados fornecidos em fevereiro de 2005. Esse índice tem como base as inscrições da população interessada nos imóveis da CDHU durante os anos 1990, e também é apresentado no relatório da Seurbem 1996 (PREFEITURA, 1996).

${ }^{11}$ A Cia. Regional de Habitações de Interesse Social (Crhis) é uma empresa de Economia Mista atuando na área da Habitação Popular, tendo construído desde 1983 um montante de 34.638 unidades residenciais distribuídas por 127 conjuntos habitacionais em diversas cidades do Estado de São Paulo (CRHIS, 2004).
} 
MEIRA, S. I. de. Planejamento e gestão urbanos em Sorocaba-SP:...

Os conjuntos ou unidades habitacionais construídos e comercializados pela CDHU na cidade de Sorocaba ${ }^{12}$ são distribuídos, de acordo com o número de unidades e a tipologia das construções (Quadro 2).

As zonas oeste e norte da cidade foram durante as décadas de 1980 e 1990 as áreas que mais receberam investimentos com relação aos programas habitacionais populares. São áreas classificadas, no zoneamento contido no Plano Diretor de Sorocaba, como zonas residenciais do tipo 3 (ZR3), em que o próprio planejamento estipula para essa localidade ações que promovam a expansão urbana neste sentido (PREFEITURA, 2004). Somente os conjuntos habitacionais da Vila Fiori e do Recreio dos Sorocabanos estão localizados em uma Zona Residencial 2 (ZR2), na porção centro-norte da cidade.

Da mesma forma que o planejamento urbano de Sorocaba, por meio do Plano Diretor, se adequou aos vetores de expansão da cidade - já que o crescimento nestas áreas é anterior à elaboração do Plano Diretor -, a especulação imobiliária se consolidou com os investimentos públicos em infra-estrutura urbana nessas áreas. É o caso que comumente acontece ao longo das avenidas Itavuvu e Ipanema, na Zona Norte da cidade.

A zona norte, caracterizada no Plano Diretor como o principal vetor de expansão da cidade (ZR3) e uma área que apresenta pequenas restrições à urbanização, além de ser a região mais populosa do município, proporciona também a proliferação de loteamentos priva- dos que se beneficiam dos investimentos públicos. É também nesta zona da cidade que foi realizada a maior parte dos programas habitacionais da prefeitura em parceria com a CDHU (Quadro 2).

Nas zonas residenciais 3 (ZR3) da porção oeste da cidade, também ocorre a participação excessiva da especulação imobiliária, com o surgimento maciço de loteamento e conjuntos habitacionais que, de certa forma, apresentam características físicas de habitações populares. No entanto, estes imóveis não correspondem com a acessibilidade proposta por instituições públicas como a CDHU, em que as unidades habitacionais custam entre sete e 35 mil reais, com parcelas de financiamento que não ultrapassam $30 \%$ da renda familiar e voltada a candidatos a mutuários com renda familiar entre 1 e 10 salários mínimos.

Normalmente, os valores dos imóveis comercializados pela iniciativa privada, com as características anteriormente mencionadas, variam em torno de 30 a 40 mil reais, e com sistema de financiamento muito diferente dos oferecidos pela CDHU (conforme levantamento de preços feito entre janeiro e dezembro de 2004).

Não há uma explicação convincente para a falta de programas da CDHU no município de Sorocaba desde o ano de 1996. De acordo o presidente estadual da CDHU, Sérgio de Oliveira Alves, em depoimento a um jornal local, a CDHU aguarda a manifestação das prefeituras para estudar a possibilidade da execução das obras, em que:

\begin{tabular}{|c|c|c|c|c|c|c|}
\hline Modalidade & $\begin{array}{l}\text { Localização do } \\
\text { Conjunto }\end{array}$ & Tipologia & $\begin{array}{l}\text { Número de } \\
\text { Unidades }\end{array}$ & $\begin{array}{c}\text { Data da } \\
\text { Comercialização }\end{array}$ & $\begin{array}{c}\text { Valor da Obra } \\
\text { Reajustado (R\$) }\end{array}$ & $\begin{array}{c}\text { Custo da } \\
\text { Unidade (R\$) }\end{array}$ \\
\hline E.G. & $\begin{array}{c}\text { Parque Vitória } \\
\text { Régia (Zona Norte) }\end{array}$ & Horizontal & 485 & 1994 & |---------- & |---------- \\
\hline E.G. & $\begin{array}{c}\text { Parque Vitória } \\
\text { Régia (Zona Norte) }\end{array}$ & Horizontal & 56 & 1996 & $422.427,24$ & $7.543,34$ \\
\hline E.G. & $\begin{array}{c}\text { Parque Vitória } \\
\text { Régia (Zona Norte) }\end{array}$ & Horizontal & 515 & 1997 & $3.655 .022,08$ & $7.097,13$ \\
\hline E.G. & $\begin{array}{c}\text { Vila Fiori (Zona } \\
\text { Norte) }\end{array}$ & Vertical & 320 & 1998 & $4.936 .563,74$ & $15.426,76$ \\
\hline $\begin{array}{l}\text { Chamamento } \\
\text { Empresarial* }^{*}\end{array}$ & $\begin{array}{c}\text { Jardim Ipatinga } \\
\text { (Zona Oeste) }\end{array}$ & Vertical & 608 & 1998 & $11.424 .976,33$ & $23.146,23$ \\
\hline TOTAL & - & ------- & 1.984 & ------------ & $20.438 .989,39$ & ----------- \\
\hline
\end{tabular}

QUADRO 2 - CONJUNTOS DA CDHU COMERCIALIZADOS EM SOROCABA ENTRE 1994 E 1998

FONTE: CDHU, 2004.

* CHAMAMENTO EMPRESARIAL, SEGUNDO O ECONOMISTA EDGARD PEREIRA (ESCRITÓRIO DA CDHU EM SOROCABA), É O SISTEMA EM QUE A CDHU CONTRATA, POR MEIO DE LICITAÇÃO, UMA EMPRESA PARA A EXECUÇÃO DA OBRA. ORGANIZAÇÃO: SANDRO IVO DE MEIRA.

12 Existe, ainda, um conjunto com 160 unidades habitacionais construído pela CDHU no Recreio dos Sorocabanos (Zona Norte), concluído mas não comercializado, sob a modalidade de Empreitada Integral (E.I.), com data base do contrato em janeiro de 2002. O valor reajustado dessa obra foi de $\mathrm{R} \$ 5.630 .733,01$, com custo por unidade de $\mathrm{R} \$ 35.192,08$ (CDHU, 2004). 
A companhia não pode ficar atrás dos municípios perguntado quem precisa ou não da nossa ajuda. A iniciativa têm [sic] que partir das prefeituras que devem ofertar uma área para a construção das habitações. Se a prefeitura não nos procura, não temos como saber se o município tem interesse nos nossos programas. (PREFEITOS, 2005)

É defendida neste artigo, a maior participação da CDHU na promoção de núcleos habitacionais na cidade, por se tratar de habitações que oferecem, ao mesmo tempo, qualidade das moradias, localização adequa$\mathrm{da}^{13}$, garantia de infra-estrutura urbana, justiça na distribuição das moradias por meio de sorteios e facilidade de pagamento para as famílias de baixa e média rendas.

No caso de Sorocaba, fica evidente a falta de participação da CDHU entre os anos de 1997 e 2004 com a paralela proliferação de conjuntos habitacionais realizados pela iniciativa privada nas áreas de maior expansão da cidade (Norte e Oeste). O que se nota, portanto, é a falta de iniciativa do poder público municipal durante o referido período, em privilégio da expansão especulativa. A orientação dos vetores de expansão fica oficializada pelo Plano Diretor de 2004 e permite a continuidade de uma prática comum em Sorocaba, que é a falta ou ineficiência de programas habitacionais em parceria com Cohabs ou com a própria CDHU, e a "entrega" à iniciativa privada do mercado de conjuntos habitacionais voltados às classes populares.

O principal programa habitacional voltado à população de baixa renda desenvolvido em Sorocaba entre os anos de 1997 e 2004 (gestões Renato Amary) é o Programa de Desfavelamento, que resultou no assentamento habitacional Ana Paula Eleutério, conhecido popularmente por Habiteto ${ }^{14}$.

A falta de políticas habitacionais nas gestões municipais anteriores é apontada pelas gestões Renato Amary (1997-2000 e 2001-2004), assim como o alto índice de fluxo de migrantes para a cidade, como os principais responsáveis pela grande ocupação irregular e desordenada que Sorocaba vive atualmente (SECID, 1997, 2-4). Isto contribui para a instalação de favelas e barracos em alguns bairros considerados de classe média ou média-alta, ou ainda, em áreas de grande periculosidade para ocupação.

A maior parte dos focos de favelização que existem atualmente na cidade está concentrada nas áreas próximas a córregos e fundos de vales, classificadas no zoneamento, em muitos casos, como Zonas de Conservação Ambiental (ZCA) e também em áreas particulares que apresentam riscos à população, onde as reivindicações por regularização são constantes e conflituosas.

Os problemas de favelização se acentuaram na cidade de Sorocaba durante a virada da década de 1970 para 1980, quando o seu índice atingiu $2 \%$ da população urbana (ZIMMERMANN, 1992, p. 172-174). Desde aquela época, as políticas habitacionais desenvolvidas para sanarem tal problema têm demonstrado uma característica de excluir seus "beneficiados" para áreas distantes dos bairros que estavam prosperando.

Para a Secretaria da Cidadania $(1997$, p. 1), o desfavelamento, desenvolvido com o Projeto do Habiteto, representa o direito de ter uma vida digna, ou seja, representa o direito à cidadania às pessoas que dele serão beneficiadas. A Secretaria da Cidadania (SECID, 1997, p. 1) considera que

ser cidadão significa ser sujeito de direitos e deveres. Cidadão é aquele que está capacitado a participar da vida da cidade, extensivamente, da vida em sociedade; no gozo de seus direitos civis e políticos, bem como no desempenho de seus deveres

E acrescenta, justificando o Projeto de Desfavelamento como uma ação que garantirá o direito de cidadania à população assistida:

No Projeto de Desfavelamento, nosso trabalho é direcionado aos moradores de áreas de risco, que normalmente são áreas verdes ou institucionais. Para nós, os indivíduos que lá residem têm também o direito à CIDADANIA. Direito este: à moradia, à escola, à saúde, ao lazer, ao transporte, etc. (SECID, 1997, p. 1)

Todo empreendimento habitacional realizado com o interesse a inclusão social da população deve levar em consideração o conceito de grupos vulneráveis, que representam uma parcela da população que sofre discriminação social por características que lhe são atribuídas:

Preconceitos e desqualificação social se expressam tanto por meio de relações étnico-raciais, como acontece com negros e índios, quanto de outros atributos de gênero, idade, local de origem ou de moradia, ori-

\footnotetext{
${ }^{13}$ A localização dos terrenos é um dos principais critérios para a aprovação ou não do empreendimento pela CDHU (CDHU, 2004).

${ }^{14}$ O Habiteto, criado em Sorocaba num Projeto de Desfavelamento da Prefeitura Municipal, não corresponde ao Programa "Habiteto" da CDHU, que consiste na promoção de programas de habitação popular para o interior do Estado de São Paulo, baseados no sistema de mutirão na construção das moradias (CDHU, 2003, p. 17, 23, 51).
} 
MEIRA, S. I. de. Planejamento e gestão urbanos em Sorocaba-SP:...

entação sexual, também frutos de hierarquias e classificações socialmente produzidas. [...] Enfim, alvo de discriminação, grupos e pessoas se apresentam em situações de acentuadas desvantagens relativas que devem ser levadas em consideração quando o objetivo é reduzir desigualdades sociais em uma perspectiva de promoção do desenvolvimento sustentável. (IBAM, 2000)

Uma política de inclusão ou reinclusão social no meio urbano, ao menos quando se trata de garantir o direito à moradia digna como pressuposto aos direitos humanos (INSTITUTO CIDADANIA, 2003, p. 03), deve se preocupar em trabalhar a questão da exclusão social e segregação espacial (aqui entendidos, aglutinadamente, como segregação/exclusão socioespacial). Estes devem ser encarados como problemas a serem resolvidos de forma emergencial e, por se tratar de uma mazela social constantemente crescente nas cidades brasileiras, de forma planejada para as ações futuras, pois:

A exclusão social emerge como uma das variáveis da urbanização deste final de milênio e como um componente da dinâmica de um processo que opera com grandes contrastes sociais e com situações de conflito latente, reflexos de uma ampla questão distributiva secularmente elaborada, e que certamente terá peso na evolução do urbano enquanto espaço de assimetrias e de contradições. (AJARA, 2000, p. 96)

O projeto de desfavelamento de Sorocaba (Habiteto) é encarado, portanto, pelas duas gestões municipais de Renato Amary (1997-2000 e 2001-2004), como o princípio para as melhorias sociais na cidade. Segundo a mesma fonte (DESFAVELAMENTO, 2003), a população favelada em Sorocaba no ano de 1998, era de 14 mil pessoas, concentradas em 59 pontos $^{15}$. No entanto, 1.080 famílias - em torno de 5.090 pessoas (CIS, 2003) - foram relocadas para o assentamento até o final de 2003 (número questionável para a atualidade, já que a própria Secretaria da Cidadania enfrenta problemas de venda ou outras formas de terceirização do uso dos lotes (DESASSENTADOS, 2003)).

Em Sorocaba, a prática adotada pelas gestões municipais no período de 1997 a 2004 fica evidente ao se comparar o Habiteto (tanto no seu início como atualmente) com as obras realizadas pela política de revitalização do centro, dos bairros nobres e das áreas propensas à especulação imobiliária.

Em se tratando de moradia popular, espera-se um efeito estrutural - e não apenas compensatório - da nova moradia, e almejam-se, principalmente, impactos positivos na redução da segregação socioespacial (RAMOS; ROCHA DE SÁ, 2003, p. 167).

Como já comentado anteriormente, a própria definição da zona norte da cidade como um vetor de expansão da área urbana de Sorocaba demonstra a legitimação pelo poder público municipal em conferir àquela área o direcionamento dos investimentos públicos em infra-estrutura urbana, ficando evidente também o aproveitamento da iniciativa privada nessas áreas com a proliferação de novos loteamentos.

A prática da remoção da população que abriga de forma irregular bairros estruturados para o Habiteto e a inibição às novas ocupações (ou invasões, como definem a Prefeitura Municipal e a Secretaria da Cidadania), congregam-se numa política espoliativa e segregativa tanto social como espacialmente.

Uma política habitacional que preza pela inclusão social e o real direito à cidadania deve levar em consideração a demanda por moradias no município a fim de atender ao déficit habitacional e a integração da população assistida social e espacialmente ao restante da sociedade, e não considerar somente o problema dos focos de favelização e direcionar suas ações na inibição contra novas ocupações, como um critério de controle da ocupação e organização do espaço urbano.

Dessa maneira, e atribuindo-se de subterfúgios, o poder público municipal de Sorocaba deixa prevalecer a política de embelezamento - em comparação aos Planos de Embelezamento a que se refere Villaça (1999, p. $192-199)^{16}$, em seu estudo sobre o histórico do planejamento urbano no Brasil -, tendendo a beneficiar mais intrinsecamente o desenvolvimento econômico (dentre eles, a presença maciça de empreendimentos imobiliários ligados à especulação em certas zonas da cidade), e colocando em segundo plano a questão social aqui evidenciada, a moradia popular, negligenciando o déficit habitacional (falta de moradias) na cidade e prorrogando as medidas para sanarem o déficit de habitabilidade (precariedade das residências) no Habiteto.

\footnotetext{
15 No início da década de 1990 a então Secretaria de Habitação apresentou em seu relatório sobre a situação habitacional de Sorocaba que, nesta cidade, os focos de favela estariam em torno de 60 núcleos, com aproximadamente 7.700 unidades habitacionais e 38.500 pessoas (PREFEITURA, 1996).

${ }^{16}$ Esse tipo de planejamento foi altamente ideológico, pois foi amplamente utilizado para glorificar e ajudar a impor o Estado e a classe dirigente capitalistas, quando eram revolucionários [nos Estados Unidos]. [...] Foi sob a égide dos planos de embelezamento que nasceu o planejamento urbano (lato sensu) brasileiro. (VILLAÇA, 1999, p. 192; 193)
} 


\section{CONSIDERAÇÕES FINAIS}

Este artigo buscou demonstrar o planejamento e gestão urbanos em Sorocaba, com enfoque à avaliação de como a questão da habitação popular foi tratada pelas administrações municipais entre 1989 e 2004.

O Plano Diretor atingiria sua meta de desenvolvimento social se apontasse no seu texto a maneira com que os instrumentos previstos pelo Estatuto da Cidade (IPTU progressivo no tempo, desapropriação com pagamento em títulos) seriam aplicados na prática no sentido de diminuir o déficit habitacional da cidade, coibir a especulação imobiliária e diminuir as ocupações irregulares. O Plano Diretor deveria também apontar as áreas da cidade propensas a estes dispositivos legais. No entanto, e por se tratar de um planejamento classificado como "físico-territorial", o Plano Diretor de Sorocaba limitou-se a apontar os diferentes usos por meio do Zoneamento Municipal.

O Plano Diretor de Sorocaba privilegiou a manutenção da "boa forma urbana", em que o tecnicismo supera as propostas sociais e a realidade social. A cidade, com seus problemas diversos, não foi enfocada neste documento, podendo-se classificar a participação popular apenas como uma participação informativa e cooptativa. Assim, a população teve uma participação na elaboração do Plano Diretor apenas para um mero cumprimento das normas estabelecidas pelo Estatuto da Cidade.

Um dos problemas verificados na análise da gestão em Sorocaba atinge diretamente os dados sobre o déficit habitacional da cidade. Estes são contraditórios, já que vários números são apresentados sem que haja um consenso nesta informação, variando de 11.000 até 30.000 moradias. A imprecisão desta informação dificulta as ações do poder público municipal na resolução de tal mazela social. No entanto, o que fica claro em Sorocaba, entre os anos de 1989 a 2004, é a mudança de postura com relação à política habitacional em dois períodos distintos: de 1992 a 1997 e de 1998 a 2004 .

No primeiro período (1992 a 1997) verifica-se uma maior participação de instituições como a CDHU e a Cohab-Crhis, que juntas construíram na cidade 5.490 moradias. Não que esse número tenha resolvido o déficit habitacional daquela época, mas representa um interesse maior da própria Prefeitura Municipal de Sorocaba em propor parcerias com os organismos especializados para a diminuição dessa carência.

Durante os anos de 1998 e 2004, período que compreende as duas gestões municipais do prefeito Renato Amary, verifica-se a não-participação das companhias habitacionais citadas anteriormente e a entrega do mercado das moradias populares exclusivamente aos incorporadores imobiliários.

A ação pública municipal na área da habitação popular neste segundo período limita-se ao Projeto de Desfavelamento conhecido como Habiteto. Nele se configura um processo de segregação socioespacial com a construção das moradias sem condições mínimas de habitabilidade. A habitabilidade é relegada a um futuro momento, quando se prevê a resolução deste problema.

Por mais que as propostas do Estatuto da Cidade apareçam nos Planos Diretores elaborados após o ano de 2001, a mera inclusão dos instrumentos de política urbana não garante a aplicação deles nas gestões públicas.

O que parece, no entanto, é que os municípios, e neste caso, Sorocaba, procuram anexar esses instrumentos a seus Planos Diretores apenas para o cumprimento da Legislação Federal.

É preciso, entretanto, que experiências ilustrem a viabilidade dos instrumentos na construção de uma cidade com mais qualidade de vida e justiça social, em que a democratização, tanto do planejamento como da gestão, pode ser um caminho para reverter esse quadro.

\section{REFERÊNCIAS}

AJARA, César. Uma pauta para reflexão sobre o urbano e o regional no Brasil dos anos 90. In: CASTRO, Iná E. de; MIRANDA, Mariana; EGLER, Cláudio A. G. (Orgs). Redescobrindo o Brasil 500 anos depois. 2 ed. Rio de Janeiro: Bertrand Brasil, 2000. p. 93-100.

BRASIL. Constituição da República Federativa do Brasil. 17. ed. São Paulo: Saraiva, 1997. (Coleção Saraiva de Legislação)
Lei n. 10.257, de 10 de julho de 2001. Regulamenta os arts. 182 e 183 da Constituição Federal, estabelece diretrizes gerais da política urbana e dá outras providências. Diário Oficial da República Federativa do Brasil, Brasília, 2001.

Plano Diretor participativo: guia para elaboração pelos municípios e cidadãos. Brasília: Ministério das Cidades, 2004. Disponível em: <http://www.cidades.gov.br>. Acesso em: 7/2/ 2005. 
MEIRA, S. I. de. Planejamento e gestão urbanos em Sorocaba-SP:...

CDHU. Programas habitacionais. Disponível em: <http:// www.cdhu.sp.gov.br>. Acesso em: 6/4/2004.

Ação da CDHU por municípios: Sorocaba. Disponível em: <http://www.cdhu.sp.gov.br>. Acessado em janeiro de 2005.

CENTRO DE INTEGRAÇÃO SOCIAL (Habiteto). Depoimentos da Assistente Social: Marilene Debortolli Cardoso. Sorocaba, em 12 fev. 2003.

COMPANHIA REGIONAL DE HABITAÇÃO DE INTERESSE SOCIAL. Conjunto Habitacional Júlio de Mesquita Filho: Sorocaba I. Disponível em: <http://www.crhis.com.br/>. Acesso em: 6/12/2004.

DÉFICIT Habitacional é de 11.687 moradias. Cruzeiro do Sul. Sorocaba, 19 jan. 2004.

DESASSENTADOS do Habiteto. Cruzeiro do Sul. Sorocaba, 14 mar. 2003.

DESFAVELAMENTO é base para melhorias. Cruzeiro do Sul. Sorocaba, 24 jan. 2003.

INSTITUTO BRASILEIRO DE ADMINISTRAÇÃO MUNICIPAL. redução das desigualdades sociais. Brasília: IBAM/PNUD, 2000.

IBGE. Censo 2000: resultados preliminares. Rio de Janeiro: IBGE, 2001.

INSTITUTO CIDADANIA. Projeto moradia. São Paulo, 2000. Disponível em: <http://www.icidadania.org.br>. Acesso em: 30/1/2003.

INSTITUTO PÓLIS. Estatuto da Cidade: guia para implementação pelos municípios e cidadãos. Brasília: Câmara dos Deputados, 2001.

KOWARICK, Lúcio. Escritos urbanos. São Paulo: Editora 34, 2000.

MAUTNER, Yvonne. A periferia como fronteira de expansão do capital. In: DÉAK, Csaba; SCHIFFER, Sueli Ramos (Orgs.).
O processo de urbanização no Brasil. São Paulo: Edusp, 1999. p. 245-260.

PLENÁRIA discute déficit habitacional amanhã. Diário de Sorocaba. Sorocaba, 07 fev. 2004.

PREFEITOS de quinze cidades assinam convênio com a CDHU. Cruzeiro do Sul. Sorocaba, 21 ago. 2005.

PREFEITURA Municipal de Sorocaba. Situação habitacional de Sorocaba. Sorocaba: Secretaria de Habitação, 1996.

Plano Diretor de Desenvolvimento Físico-Territorial de Sorocaba: Lei n. 7.122 de 01 de junho de 2004. Disponível em: <http://www.sorocaba.sp.gov.br>. Acesso em: 7/6/ 2004.

PROMOTOR aponta "imperfeições" no texto e propõe retirada da votação. Cruzeiro do Sul. Sorocaba, 08 out. 2003.

RAMOS, Maria Helena Rauta; ROCHA DE SÁ, Maria Elvira. Avaliação da política de habitação popular segundo critérios de eficácia societal. In: RAMOS, Maria Helena Rauta (Org.). Metamorfoses sociais e políticas urbanas. Rio de Janeiro: DP\&A, 2003. p. 151-168.

SECRETARIA DA CIDADANIA DO MUNICÍPIO DE SOROCABA. Projeto de desfavelamento de Sorocaba. Sorocaba, jul. 1997.

SOUZA, Marcelo Lopes de. Mudar a cidade: uma introdução crítica ao planejamento e à gestão urbanos. 2. ed. Rio de Janeiro: Bertrand Brasil, 2003.

VILLAÇA, Flávio. Uma contribuição para a história do planejamento urbano no Brasil. In: DÉAK, Csaba; SCHIFFER, Sueli Ramos (Orgs.). O processo de urbanização no Brasil. São Paulo: Edusp, 1999. p. 169-244.

ZIMMERMANN, G. A região administrativa de Sorocaba. São Paulo: Fundação Seade: 1992. p. 38. 